\begin{tabular}{|l|l|l|}
\hline \multicolumn{2}{|c|}{ PublisherInfo } \\
\hline \hline PublisherName & $:$ & BioMed Central \\
\hline \hline PublisherLocation & $:$ & London \\
\hline \hline PublisherImprintName & $:$ & BioMed Central \\
\hline \hline
\end{tabular}

\title{
CD28-deficient MRL/Mpj-lpr/lpr mice
}

\begin{tabular}{|l|l|l||}
\hline \multicolumn{2}{|c|}{ ArticleInfo } \\
\hline \hline ArticleID & $:$ & 238 \\
\hline \hline ArticleDOI & $:$ & $10.1186 /$ ar-1999-66733 \\
\hline \hline ArticleCitationID & $:$ & 66733 \\
\hline \hline ArticleSequenceNumber & $:$ & 195 \\
\hline \hline ArticleCategory & $:$ & Paper Report \\
\hline \hline ArticleFirstPage & $:$ & 1 \\
\hline \hline ArticleLastPage & $:$ & 3 \\
\hline \hline & & RegistrationDate : 1999-9-27 \\
\hline ArticleHistory & $:$ & OnlineDate \\
\hline ArticleCopyright & $:$ & Current Science Ltd1999-9-27 \\
\hline \hline ArticleGrants & $:$ & \\
\hline \hline ArticleContext & $:$ & 130753311 \\
\hline \hline
\end{tabular}


Aff1 Imperial College School of Medicine, London, UK

\section{Keywords}

Autoimmune disease, CD28, lupus, MRL/lpr

\section{Context}

The MRL/Mpj-lpr/lpr (MRL/lpr) mouse spontaneously develops autoimmune disease resembling systemic lupus erythematosus in humans. Various studies have demonstrated the critical role of T cells in the development of autoimmune disorders in MRL/lpr mice. Successful T cell activation generally requires a primary signal through the TCR coupled with a secondary signal provided by costimulatory molecules. CD28 provides the most effective costimulatory signal for T cell activation. The treatment of NZB/NZW lupus-prone mice with CTLA4-Ig has implicated the involvement of CD28 in lupus [Finck et al, Science 1994, 265:1225-1227(Abstract)]. Further studies on the crucial role of CD28 in the development of autoimmune disease are now possible using CD28-deficient lupus-prone mice. Examination of the involvement of CD28 costimulation in development of autoimmune disease through the generation of gene-targeted CD28-deficient MRL/lpr mice.

\section{Significant findings}

The spleens of CD28-/- lpr/lpr mice were larger than those of CD28+/+ lpr/lpr mice due to an increase in B220+ TCRa?+ cells, although the number of these cells in the lymph nodes remained unaltered. CD28-/- lpr/lpr mice produced significantly less serum IgG1, IgG2a, and IgG3 than CD28+/+ lpr/lpr mice, whereas levels of $\operatorname{IgG} 2 \mathrm{~b}$ and IgM remained unchanged. Also the ratio of serum IgG1/IgG2a was lower in CD28-/- lpr/lpr mice, indicating that the absence of CD28 may suppress serum IgG1 more severely than IgG2a in MRL/lpr mice. Anti-DNA antibodies of the IgG1, IgG2a, IgG2b and IgG3 subclasses were significantly decreased in CD28-deficient mice, whereas IgM anti-DNA antibody levels were no different from those in $\mathrm{CD} 28+/+\mathrm{lpr} / \mathrm{lpr}$ mice. Also, whereas both mouse genotypes produced similar IgM rheumatoid factor levels, CD28-/- lpr/lpr mice showed significantly decreased IgG rheumatoid factor levels. Glomerular lesions and vascular lesions in CD28-/- lpr/lpr mice were less severe than those observed in CD28+/+ lpr/lpr mice. Only mild mesangial proliferation was shown and, in contrast to the dense perivascular and interstitial infiltration of inflammatory cells observed in $\mathrm{CD} 28+/+$ lpr/lpr mice, no cellular infiltration was observed in CD28-/- lpr/lpr mice, and only mild IgG deposits were noted in the mesangium. The progression of nephritis was assessed in older CD28-/- lpr/ 
lpr mice ( $>24$ weeks of age); perivascular and interstitial infiltration were not detected in the kidneys but glomerulonephritis did progress. Inflammatory infiltration was not observed in livers, lungs or the ankle joints and the mortality rate was decreased in CD28-/- 1pr/lpr mice (at 20 and 25 weeks of age, 100\% and $70 \%$, respectively, of CD28-/- lpr/lpr mice were alive compared with $61.5 \%$ and $30.8 \%$, respectively, of CD28+/+ lpr/lpr mice).

\section{Comments}

This paper clearly demonstrates convincing evidence that CD28 plays a critical role in the development of many aspects of autoimmune disease in MRL/lpr mice, thus enhancing our understanding of the molecular basis behind the progression of lupus. The authors have revealed that complete abolition of vasculitis, arthritis and cellular infiltration into organs can be achieved through lack of CD28 costimulation. As with all studies involving MRL/lpr mice the relevance to human lupus is questionable as the lpr defect (due to a mutation in Fas) has no counterpart in the human disease. Nevertheless common elements of the disease are found in MRL/lpr mice which, along with other strains of lupus-prone mice, have proved invaluable in assessing the effector mechanisms involved in the progression of autoimmune disease. Indeed the striking inhibition of disease seen in this paper strongly promotes the blockade of CD28 costimulation as a legitimate target for therapy of autoimmune disorders.

\section{Methods}

CD28-deficient mice were backcrossed to MRL/lpr mice for four generations and genotyped using polymerase chain reaction (PCR). Lymph node cells and spleen cells were analysed using flow cytometry and serum samples were assayed for IgG1, IgG2a, IgG2b, IgG3 and IgM by ELISA. AntiDNA antibodies were assayed by ELISA on plates coated with native calf-thymus-DNA; predominantly anti-dsDNA antibodies were detected. IgG and IgM rheumatoid factor was also measured by ELISA. Histopathological examination was carried out on kidneys, livers, lungs and ankles and immunofluorescence was performed on kidney tissue to evaluate the presence of glomerular IgG deposits. Most comparisons between CD28+/+ lpr/lpr and CD28-/- lpr/lpr mice were carried out when mice were 18 weeks of age.

\section{References}

1. Tada Y, Nagasawa K, Ho A, Morito F, Koarada S, Ushiyama O, Suzuki N, Ohta A, Mak TW: Role of the costimulatory molecule CD28 in the development of lupus in MRL/lpr mice. J Immunol. 1999, 163: 3153-3159.

This PDF file was created after publication. 